\title{
B-glucana de Saccharomyces cerevisiae: constituição, bioatividade e obtenção
}

\author{
ß-glucana from Saccharomyces cerevisiae: \\ constitution, bioactivity and obtaining
}

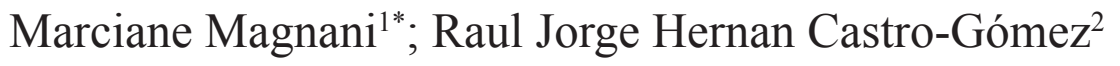

Resumo

$\beta$-glucanas são polissacarídeos constituintes estruturais da parede celular de leveduras, fungos e alguns cereais, que se diferenciam pelo tipo de ligação presente entre as unidades de glicose. Uma importante fonte destes polissacarídeos é a parede celular de Saccharomyces cerevisiae, uma levedura amplamente empregada em processos industriais de fermentação. A $\beta$-glucana é considerada um modificador da resposta biológica devido ao seu potencial imunomodulador, pois ao ser reconhecida por receptores celulares específicos tem habilidade de realçar a resposta imune do hospedeiro. Outros efeitos benéficos como anticarcinogênico, antimutagênico, hipocolesterolêmico e hipoglicêmico também têm sido relacionados à $\beta$-glucana Esta revisão de literatura teve por objetivo agregar conhecimentos científicos sobre a constituição e bioatividade da $\beta$-glucana, incluindo seu reconhecimento pelo sistema imune, bem como, a obtenção a partir da parede celular de S. cerevisiae.

Palavras-chave: $\beta$-glucana, Saccharomyces cerevisiae, bioatividade, imunomodulador, sistema imune

\begin{abstract}
$\beta$-glucans are polysaccharides that constitute the structure of the cell wall of yeast, fungi and some cereals, which differs each other by the linkages between glucose units. An important source of these polymers is the Saccharomyces cerevisiae cell wall, which is a yeast widely used in industrial processes of fermentation. The $\beta$-glucan is considered to be a modifier of biological response due to its immunomodulator potential. When it is recognized by specific cellular receptors, have the ability to enhance the host's immune response. Other beneficial effects such as anticarcinogenic, antimutagenic, hypocholesterolemic and blood sugar reduction have also been related to the $\beta$-glucan. The aim of this literature review was expand scientific knowledge about the constitution and bioactivity of $\beta$-glucan, including its recognition by the immune system, as well as its obtaining from $S$. cerevisiae cell wall.
\end{abstract}

Key words: $\beta$-glucan, Saccharomyces cerevisiae, bioactivity, immunomodulator, immune system

${ }^{1}$ Doutoranda em Ciência de Alimentos, DCTA, CCA; UEL. E-mail: magnani2@bol.com.br

2 Professor doutor titular do DCTA; CCA; UEL.

Autor para correspondência 


\section{Introdução}

$\beta$-glucanas são polissacarídeos constituintes estruturais da parede celular de leveduras, fungos e alguns cereais, que se diferenciam pelo tipo de ligação entre as unidades de glicose da cadeia principal e pelas ramificações que se conectam a essa cadeia. Nas últimas décadas estes polímeros vem recebendo especial atenção por sua bioatividade, principalmente no que se refere a imunomodulação. Além disso, inúmeros efeitos benéficos como antitumoral, antinflamatório, antimutagênico, hipocolesterolêmico e hipoglicêmico têm sido relacionados à $\beta$-glucanas. Uma importante fonte de $\beta$-glucana é a parede celular de Saccharomyces cerevisiae, também conhecida como levedura de fermentação, que é amplamente empregada nas indústrias de panificação, cervejaria e sucroalcoleira. Em $S$. cerevisiae, a $\beta$-glucana é constituída por um esqueleto linear central de unidades de glicose ligadas na posição $\beta(1-3)$, com cadeias laterais unidas em $\beta(1-6)$, que ocorrem em diferentes intervalos e têm tamanhos variados. A $\beta$-glucana é designada como um modificador da resposta biológica pois, ao ser reconhecida pelo organismo desencadeia uma série de eventos na resposta imune. Em vertebrados este reconhecimento ocorre através de receptores específicos de superfície celular e em seguida o sistema imune é estimulado pela $\beta$-glucana em resposta a inúmeras situações prejudiciais ao indivíduo. A modulação da $\beta$-glucana inclui a ativação de macrófagos e linfócitos polimorfonucleares, além da indução da expressão de diversas citocinas. O mecanismo de ação parece estar relacionado ao peso molecular, tipo de ligações glicosídicas, resíduos presentes, solubilidade em água, conformação espacial e grau de polimerização da $\beta$-glucana. Nos últimos anos, inúmeras pesquisas tem sido realizadas visando à otimização do processo de obtenção da $\beta$-glucana a partir da parede celular de $S$. cerevisiae. Além disso, há um crescente interesse na identificação das características estruturais e biológicas da $\beta$-glucana e seus derivados, na expectativa de viabilizar seu uso, aproveitando seu potencial imunoestimulante. Esta revisão teve como objetivo aprofundar conhecimentos sobre este importante biopolímero, enfatizando sua obtenção a partir de $S$. cerevisiae, pois representa um potencial adjuvante na profilaxia e terapia de inúmeras doenças.

\section{Parede celular de Saccharomyces cerevisiae}

Designada comumente como levedura de cervejaria ou de panificação, Saccharomyces cerevisiae é um microrganismo eucariótico unicelular, que apresenta forma variada. Dentre suas características, destaca-se a capacidade de ajustarse metabolicamente para a fermentação de açúcares em presença ou ausência de oxigênio, produzindo álcool ou gás carbônico (TORTORA; BERDELL; CASE, 2000).

O desenvolvimento de uma camada de proteção externa é crítico para o crescimento e sobrevivência das células fúngicas (DURÁN; NOBLEGA, 2004). A parede celular é uma organela comum em leveduras e fungos filamentosos, localizada na interface entre o microrganismo e o meio ambiente. Nas últimas décadas, sua organização e composição vêm sendo amplamente estudadas (FIRON; LESSAGE; BUSSEY, 2004).

A parede celular é uma estrutura forte, responsável pela proteção física e estabilidade osmótica da célula que através de permeabilidade seletiva permite o transporte de nutrientes para o citoplasma (SMITH et al., 2000; KLIS et al., 2002). Neste contexto, Kapteyn et al. (1997) relataram que a parede é determinante para a integridade da célula, pois sustenta a forma e oferece proteção mecânica, além de promover o metabolismo e crescimento celular pela modulação da seletividade às macromoléculas. Além disso, para preservar a integridade da célula, quando ocorrem perturbações na parede celular mecanismos de reparo reorganizam a estrutura molecular (KLIS et al., 2002). 
Em S. cerevisiae, a parede celular representa de 15 a $30 \%$ do peso seco total da célula, sendo que seus componentes são sintetizados e unidos em sincronia com o crescimento e a divisão celular (CID et al., 1995).

Estudos sobre a composição da parede de células de $S$. cerevisiae revelaram a presença de glucana (48-60\%), que é um polímero de unidades de glicose com ligações $\beta(1-3)$ e $\beta(1-6)$, manoproteínas (20$23 \%)$, quitina $(0,6-2,7 \%)$, que é composta por $\beta(1-$ 4) N-acetilglicosamina e uma pequena porção de lipídios (FLEET, 1985; HARTLAND et al., 1994; KLIS, 1994). A distribuição destes componentes está organizada em duas camadas principais, sendo a externa composta de manoproteínas e, a interna de glucana e quitina, em uma estrutura interconectada por ligações covalentes (HA et al., 2002; KLIS et al., 2002).

A camada externa de manoproteínas retém as proteínas periplasmáticas, conferindo resistência às células vivas de leveduras e limitando o acesso de enzimas externas, como aquelas elaboradas por outros microrganismos (ZIOTNIK et al., 1984). Em contrapartida, a camada de glucana entrelaçada por fibrilas de quitina, adjacente a membrana plasmática, mantém a rigidez e a forma da célula (KOPECKÁ; PHAFF; FLEET, 1974; KAPTEYN et al., 1997). Conforme Kollár et al. (1997), na camada interna, os componentes ligados covalentemente oferecem força e resistência pela formação de complexos macromoleculares.

A arquitetura molecular da parede celular de $S$. cerevisiae não é fixa e durante o ciclo celular sofre consideráveis ajustes na composição e estrutura (SUZUKI et al., 2004). Conforme Firon, Lesage e Bussey (2004) a parede da célula é alvo de inúmeras mudanças, e características como plasticidade e força de tensão são continuamente alteradas durante o ciclo celular, para permitir o crescimento e divisão. Além disso, também apresenta alterações em resposta à disponibilidade de nutrientes, oxigênio, e à condições de temperatura e $\mathrm{pH}$, formando complexos específicos de proteínas e polissacarídeos (KAPTEYN; VAN OEN ENOE; KLIS, 1999). Em recente estudo, Karreman et al. (2007) relataram que a Hsp12p, uma proteína hidrofílica de resposta ao stress, influencia na rigidez e permeabilidade, além de aumentar a flexibilidade da parede celular de $S$. cerevisiae. A regulação para expressão desta proteína é vinculada a condições de aumento da temperatura, pressão osmótica e concentração salina ou ainda, perturbações na parede da célula.

Kim e Yun (2006) estudaram a influência da composição do meio e das condições de cultivo na composição da parede celular de $S$. cerevisiae. As alterações no conteúdo de $\beta$-glucana, durante o cultivo em batelada e fermentação contínua, evidenciaram que a composição da parede celular é afetada pela composição do meio, principalmente na fase estacionária, quando a taxa de crescimento é baixa e a parede apresenta mudanças inclusive nas características de força e resistência.

Morris et al. (1996) relataram que a parede celular, em $S$. cerevisiae, é altamente elástica, pois as células podem diminuir rapidamente seu volume em soluções hipertônicas como resposta à pressão osmótica, e retornar ao volume original em condições ambientais favoráveis. Segundo Rees et al. (1982), a propriedade de elasticidade pode ser atribuída às cadeias de $\beta(1-3)$ glucana organizadas numa espécie de mola flexível de extensão variada. Esta organização na parede permite o aumento ou redução do volume celular em resposta às condições externas e explica, em parte, a maior permeabilidade em células vivas do que na parede isolada (De NOBEL et al., 1990; De NOBEL; BARNETT, 1991). Já, a $\beta(1-6)$ glucana serve de âncora para a estrutura e integridade da camada de manoproteínas (ROEMER et al., 1994), sendo sua síntese vinculada a expressão de genes de proteínas específicas e características da parede celular (SIMONS; EBERSOLD; HELENIUS, 1998). 


\section{$\beta$-glucanas: constituição e características}

As $\beta$-glucanas são moléculas altamente ordenadas, que se diferenciam pelo tipo de ligação entre as unidades de D-glicose (anéis tipo $\beta$-D-glucopiranose) da cadeia principal e, pelas ramificações que se conectam a essa cadeia (BROWN; GORDON, 2001).

Uma importante fonte de $\beta$-glucana é a parede celular de leveduras, particularmente da levedura de fermentação $S$. cerevisiae (DIJKGRAAF; LI; BUSSEY, 2002). Isto porque, o componente presente em maior quantidade na parede celular de $S$. cerevisiae é uma $\beta$-glucana constituída por um esqueleto linear central de unidades de glicose ligadas na posição $\beta(1-3)$, com cadeias laterais de tamanhos variados, também de glicose porém, unidas em $\beta(1$ 6). As cadeias laterais podem ocorrer em diferentes intervalos ao longo do esqueleto central (MANNERS et al., 1973; Di LUZIO et al., 1979).

Amplamente distribuídas na natureza, as $\beta$ glucanas estão presentes em fungos, leveduras, algas, bactérias e plantas superiores apresentando diferentes estruturas (MIURA et al., 2003). Em cereais, como cevada e aveia, a $\beta$-glucana da parede do endosperma apresenta, além de $\beta(1-3)$, ligações $\beta(1-4)$, formando polímeros complexos de polissacarídeo-proteína (BHATTY, 1993). De modo geral, embora ligações $\beta(1-4)$, ou $\beta(1-6)$ possam estar presentes na estrutura, além de $\beta(1-3)$, os estudos relatam estes polímeros somente como glucana ou $\beta$-glucana (FREIMUND et al., 2003). Em seu estudo, Pelosi et al. (2003) comentaram que também o nome genérico $\beta(1-3)$ glucana é utilizado para referência a glucanas contendo somente ligações $\beta(1-3)$, ou além destas, porção variável de $\beta(1-4)$ ou $\beta(1-6)$ conectadas a cadeia principal.

Quanto a solubilidade em álcali, duas frações de $\beta(1-3)$ glucana são encontradas na parede celular de $S$. cerevisiae, sendo uma solúvel e outra insolúvel. A porção insolúvel contém de 3 a $6 \%$ de ramificações unidas em $\beta(1-6)$ e representa o maior componente da parede. A porção solúvel, que representa de 15 a $20 \%$ tem estrutura semelhante a insolúvel, porém com maior número de ramificações $\beta(1-6)$ (MANNERS et al., 1973; SHAHINIAN; BUSSEY, 2000). Conforme Kapteyn et al. (1997) os heteropolímeros $\beta(1-3) / \beta(1-6)$ glucana identificados como alcalino-solúveis em $S$. cerevisiae, tornam-se alcalino-insolúveis através da ligação entre o resíduo terminal reduzido $\beta(1-4)$ da quitina e o terminal não reduzido da $\beta(1-3)$ glucana.

As $\beta(1-3)$ glucanas têm tamanho estimado de 1500 resíduos de glicose e as $\beta(1-6)$ glucanas apresentam de 150 a 200 resíduos e, na parede de $S$. cerevisiae são rearranjadas por ramificações introduzidas por glicosiltransferases (STRATFORD, 1994). Segundo Lee et al. (2002), a solubilidade em água depende do número de resíduos de glicose unidos em $\beta(1-6)$ das cadeias laterais, e do grau de polimerização. E, de acordo com Klis et al. (2002) o grau de polimerização da $\beta(1-3)$ glucana pode variar com as condições em que a levedura se encontra. Neste contexto, sabe-se que proteínas essenciais para a síntese da $\beta$-glucana são dependentes de condições ambientais (CABIB; DRGANOVÁ; DRGON, 1998).

Considerando as estruturas tri-dimensionais já observadas, $\beta(1-3)$ glucanas com a mesma composição química podem apresentar conformação de hélice simples, tripla hélice ou em forma de espiral (YOUNG; JACOBS, 1998). As hélices são compostas poruma, ou três cadeias de polissacarídeos que permanecem unidas por pontes de hidrogênio (LIPKE, 1998), formando uma estrutura helicoidal. Aparentemente, pelo menos uma porção da $\beta(1-$ 3)glucana assume estrutura helicoidal (KRAINER et al., 1994).

Dentre as conformações já descritas, a hélice simples e a tripla hélice são consideradas biologicamente ativas. Porém, a conformação em tripla hélice é sugerida como aquela que apresenta maior atividade biológica (HA et al., 2002; KO; LIN, 2004). 


\section{Bioatividade da $\beta$-glucana}

Alguns polissacarídeos, como $\beta$-glucanas obtidas de fungos, bactérias e leveduras pertencem a uma classe de substâncias conhecidas como modificadores da resposta biológica (MRBs), pois alteram a resposta no hospedeiro pelo estímulo do sistema imune (BOHN; BeMILLER, 1995). Esses polímeros ativam a resposta imune via sistema complemento, diretamente ou, com auxílio de anticorpos, e produzem fatores quimiotáticos que induzem a migração de leucócitos para o sítio da infecção (NICHOLAS; SHAUN, 2001).

As propriedades biológicas de preparações brutas de $\beta(1-3)$ glucanas vem sendo estudadas desde a década de 50 (PILLEMER et al., 1956) após a obtenção do zymosan, que é o extrato insolúvel da parede celular de S. cerevisiae (HASSID; JOSLYN; McCREADY, 1941). Descrita por DiCarlo e Fiore (1958) a composição do zymosan inclui proteínas, quitina, $\beta$-glucana, mananas e lipídeos, sendo a $\beta$-glucana o constituinte biologicamente ativo (FITZPATRICK; DiCARLO, 1964).

Utilizado como um modificador da resposta biológica, o zymosan é reconhecido como ativador de uma via alternativa do sistema complemento (HIDA et al., 2006). Desde sua descoberta diversos estudos das funções imunes, in vivo e in vitro, envolvendo $\beta$-glucanas foram realizados (BROWN; GORDON, 2003).

A atividade biológica da $\beta$-glucana vem sendo estudada com atenção nos últimos anos especialmente, pela habilidade em ativar mecanismos de defesa no hospedeiro (YUN et al., 2003; KO; LIN, 2004; KIM et al., 2006). Além disso, outros efeitos, como antitumoral, antinflamatório, antimutagênico, hipocolesterolêmico, hipoglicêmico e proteção contra infecções vêm sendo avaliados e comprovados (KOGAN, 2000; LIN et al., 2004; BEHALL et al., 2006; KIM et al., 2006). A $\beta$ glucana é considerada um candidato promissor para uso como agente imunoestimulante em pacientes imunocomprometidos, pois estes ficam mais propensos à infecção por bactérias multiresistentes a drogas (KULICKE; LETTAU; THIELKING, 1997).

E, conforme Kim e Yun (2006), a $\beta$-glucana obtida da parede celular de leveduras parece ser mais efetiva do que aquelas obtidas de outras fontes.

\section{Atividadeimunomodulatória: reconhecimento da $\beta$-glucana pelo sistema imune}

A $\beta$-glucana é designada como um modificador da resposta biológica, pois, ao ser reconhecida pelo organismo possui a capacidade de desencadear uma série de eventos na resposta imune $(\mathrm{BOHN}$; BeMILLER, 1995). Seureconhecimentopelosistema imune de vertebrados foi primeiramente descrito em estudos envolvendo patógenos fúngicos (ADEREM; ULEVITCH, 2000). Neste aspecto, é sabido que alguns fungos patogênicos mascaram sua $\beta$-glucana, ou pelo menos parte dela, evitando o reconhecimento pelas células de defesa do hospedeiro e, assim minimizando significativamente as respostas próinflamatórias para a infecção (HERRE et al., 2004). Essa camuflagem da $\beta$-glucana, que é resultado da expressão de genes sabidamente conservados em fungos, também favorece a colonização comensal de fungos oportunistas, que por sua vez tornam o hospedeiro mais propenso a doenças (WHEELER; FINK, 2006).

As respostas à $\beta$-glucana em vertebrados têm início com o reconhecimento por receptores presentes na superfície celular (BROWN; GORDON, 2005). Estes receptores já foram identificados em células imunes como macrófagos/ monócitos, neutrófilos e células natural killer (NK). Além disso, também foram descritos em células não imunes como endoteliais, fibroblastos, do epitélio alveolar e de Langerhans (BROWN; GORDON, 2003). Conforme Tokunaka et al. (2002), o reconhecimento da $\beta$-glucana pelos receptores pode ser influenciado pela solubilidade do polissacarídeo. Também a conformação do polímero em solução foi sugerida por Chorvatovicová, Machová e Sandula 
(1996) como um importante fator para a ligação aos receptores de uma dada atividade biológica.

A estrutura que permite o reconhecimento pelo sistema imune está associada a padrões moleculares (PAMPs), que normalmente são essenciais para sobrevivência de patógenos microbianos. Entre as PAMPs mais conhecidas estão as $\beta$-glucanas que desencadeiam respostas para proteger o hospedeiro contra invasão de patógenos, caracterizando a imunidade inata de organismos superiores (BROWN; GORDON, 2005).

Inúmeros receptores estão relacionados ao reconhecimento da $\beta$-glucana em vertebrados, incluindo dectin-1, Receptor do Sistema Complemento 3 (CR3), lactosilceramida e scavenger receptors. O mecanismo de resposta parece ser mediado pela combinação destes (BATTLE et al., 1998), porém o papel melhor esclarecido é o da dectin-1.

Caracterizada como uma glicoproteína transmembrana tipo II, a dectin-1 possui um domínio extracelular CDR responsável pelo reconhecimento de carboidratos e, uma cauda citoplasmática com o imunoreceptor ITAM (tirosine-based activating motif). O imunoreceptor pode ser fosforilado pelo estímulo da molécula de $\beta$-glucana e, ao que tudo indica, esta fosforilação está envolvida na produção de superóxido pelos macrófagos em resposta de defesa (BROWN; GORDON, 2001).

A expressão da dectin-1 é predominante em monócitos, macrófagos, linhagens de neutrófilos e células dendríticas, sendo significativamente influenciada por citocinas e produtos microbianos (TAYLOR et al., 2002; WILLMENT; GORDON; BROWN, 2001). Embora seja expressa de forma heterogênea nos tecidos, dectin-1 é um receptor que tem distribuição consistente com a tarefa de vigilância contra patógenos (REID et al., 2004). Esta glicoproteína reconhece $\beta$-glucanas solúveis e particuladas, incluindo partículas fúngicas intactas e também possui um ligante para células $\mathrm{T}$ (ARIIZUMI et al., 2000; STEELE et al., 2003).
A dectin-1 pode fazer a mediação de diversas respostas celulares incluindo fagocitose, endocitose e burst oxidativo. Adicionalmente, em colaboração com receptores toll-like, dectin-1 pode induzir a produção de citocinas e quimiocinas próinflamatórias como Fator de Necrose Tumoral Alfa (TNF- $\alpha$ ), Proteína Inflamatória de Macrófagos2 (MIP-2) e Interleucina-12 (IL-12) (BROWN; GORDON, 2003; GANTNER et al., 2003; HERRE et al., 2004). De acordo com Balloy et al. (2005) os receptores celulares toll-like disparam no sistema imune uma complexa sinalização em cascata após o reconhecimento de partículas fúngicas.

Outro receptor envolvido no reconhecimento e resposta imune para a $\beta$-glucana é o CR3, uma integrina heterodimérica expressa em células mielóides, NK e alguns linfócitos. CR3 possui um sítio de ligação para carboidratos, localizado no carbono terminal, e funciona como molécula de adesão celular, além de receptor fagócito para a $\beta$-glucana (THORNTON et al., 1996; XIA; ROSS, 1999). Este receptor estimula a secreção de citocinas em células NK, principalmente na presença de patógenos (ROSS et al., 1999) contudo, seu mecanismo de ação não é conhecido em detalhes (GANTNER et al., 2003).

Encontrado em diversos tipos de células, o receptor de superfície lactosilceramida é um glicoesfingolipídio que forma microdomínios na membrana plasmática. A interação deste receptor com a $\beta$-glucana realça o burst oxidativo e as funções antimicrobianas, induz a ativação da citocina Fator Nuclear kappa B (NFкB) e a produção da MIP-2 nas células do epitélio alveolar (WAKSHULL et al., 1999; HAHN et al., 2003).

Existe também um grupo heterogêneo de moléculas, chamado Scavenger receptors que reconhece lipoproteínas modificadas de baixa densidade (PEISER, MUKHOPADHYAY, GORDON, 2002) e que é capaz de reconhecer a estrutura básica da $\beta$-glucana. Sua expressão ocorre em algumas células mielóides e endoteliais e parece 
que estas moléculas estão envolvidas na homeostase e imunidade, porém, sua afinidade para carboidratos é significativamente afetada pela quantidade de polímeros (RICE et al., 2002).

\section{Atividade imunomodulatória da $\beta$-glucana}

O efeito imunomodulador das $\beta$-glucanas está envolvido tanto na imunidade humoral quanto na celular (SOLTÝS; QUINN, 1999, TOKUNAKA et al., 2002; TAKAHASHI et al., 2001; KUBALA et al., 2003). O sistema imune do hospedeiro é estimulado pela $\beta$-glucana em resposta à formação de tumores (KOGAN et al., 2002; KHALIKOVA et al., 2005) e contra infecções (TZIANABOS, 2000). Existem diversos relatos que comprovam o efeito imunomodulatório em infecções de origem bacteriana (TZIANABOS; CISNEROS, 1996; LIANG et al., 1998), viral (REYNOLDS et al., 1980; JUNG et al., 2004), fúngica (MEIRA et al., 1996) e parasitária (HOLBROOK; COOK; PARKER, 1981).

Os mecanismos envolvidos na resposta imune desencadeada pela $\beta$-glucana incluem estímulo da hematopoiese (HOFER; POSPISIL, 1997), ativação de macrófagos, neutrófilos e de células NK (LEE et al., 2001; BROWN; GORDON, 2001; XIAO; TRINCADO; MURTAGH, 2004). Neste contexto, Kubala et al. (2003) relataram que a modulação da atividade celular da $\beta$-glucana inicia com a ativação de macrófagos, células endoteliais e dendríticas, células B e T, e, linfócitos polimorfonucleares. Além disso, envolvem a resposta imune específica pela indução da expressão de diversas citocinas como TNF- $\alpha$, IL-6, IL-8 e IL-12 (Di RENZO; YEFENOF; KLEIN, 1991; LEE et al., 2001; TSIAPALI et al., 2001; XIAO; TRINCADO; MURTAGH, 2004; MOON et al., 2005). A relação entre a resposta de defesa desencadeada pela $\beta$-glucana e a produção de mediadores específicos vem sendo estudada na busca de esclarecimento dos mecanismos envolvidos. Sob este aspecto, Berner et al. (2005) sugeriram a possibilidade de sinergismo entre a $\beta$-glucana e a citocina Interferon Alfa (IFN- $\alpha$ ) na diminuição do limiar de sensitividade da resposta imune inata para patógenos fúngicos.

Como biomodulador, a $\beta$-glucana apresenta ainda habilidade para deprimir respostas próinflamatórias associadas à septicemia bacteriana. Isto ocorre através da remoção de óxido nítrico e células produtoras de citocinas do tipo TNF- $\alpha$, IL1 e IL-6 dos locais de inflamação, e aumento dos níveis de mediadores antinflamatórios, como IL-10 e Proteína Quimiotática de Monócitos-1 (MCP-1). Dessa forma, o efeito imunomodulador diminui a possibilidade de choque endotóxico e morte do hospedeiro (TZIANABOS, 2000). Em seu estudo, Luhm et al. (2006) relataram que a imunomodulação pela $\beta$-glucana em respostas pró-inflamatórias envolve após a ligação do receptor com a $\beta$-glucana, uma sinalização em cascata mediada pela IL-1 para que a reação de defesa pró-inflamatória seja alterada para uma resposta imune antiinflamatória. Pelo exposto, conhecer a ação de um imunomodulador é importante, pois permite identificar aspectos que melhoram a resposta imune do hospedeiro durante $o$ curso de uma infecção e, adotar estratégias para sua prevenção (TZIANABOS, 2000).

O mecanismo de ação imunomodulatória das $\beta$-glucanas ainda não está totalmente esclarecido, mas parece estar relacionado ao peso molecular, tipo de ligações glicosídicas, resíduos presentes, solubilidade em água, conformação espacial e grau de polimerização (OHNO et al., 1996; TOKUNAKA et al., 2002; FREIMUND et al., 2003; KUBALA et al., 2003). Conforme Manners (1973), variações estruturais em uma molécula como ramificações, tipo de ligações presentes e peso molecular podem definir seu mecanismo de ação, que é fundamental para a modulação do sistema imune.

O grau de ramificação pode influenciar na bioatividade da $\beta$-glucana. Conforme relatado por Chorvatovicová, Machová e Sandula (1996) a solubilidade da $\beta$-glucana depende do grau de ramificação, sendo que aquelas altamente ramificadas 
são solúveis em água. Então, supostamente, $\beta$ glucanas com elevado grau de ramificações e, consequentemente solúveis, seriam mais eficientes na ativação da resposta imune do hospedeiro.

Outro fator que pode contribuir para a atividade biológica da $\beta$-glucana é sua longa permanência nos sistemas de mamíferos, em virtude da ausência de $\beta$-glucanases (BROWN; GORDON, 2003). Isto permite que o polímero fique acumulado no fígado, baço e outros órgãos do sistema reticuloendotelial sem sofrer mudanças estruturais significativas. A metabolização da $\beta$-glucana é muito lenta e ocorre principalmente por oxidação (NONO et al., 1991; SUDA et al., 1992; MIURA et al., 1998), ou pela secreção através de filtração glomerular (SUDA et al., 1996). Um estudo realizado por Ohno et al. (1999) sugeriu relação entre a longa permanência da $\beta$-glucana no organismo dos mamíferos e sua atividade imunoestimulante. Após obter uma $\beta$ glucana solubilizada por oxidação, com estrutura possivelmente similar àquela depositada em mamíferos, a atividade biológica foi avaliada, sendo constatado estímulo para biossíntese de IL-8 e atividade antitumoral.

O peso molecular do polissacarídeo também parece estar relacionado com a atividade biológica. $\beta$-glucanas de elevado peso molecular ativam diretamente leucócitos, estimulando a atividade fagocítica e citotóxica, bem como a produção de mediadores pró-inflamatórios como citocinas e quimiocinas (WILLIAMS; MUELLER; BROWDER, 1996; BROWN; GORDON, 2003), consideradas mediadores chave da resposta imune humoral para uma infecção (OHATA et al., 2003). Ainda no que se refere ao peso molecular, é sabido que $\beta$-glucanas de peso molecular intermediário ou baixo possuem atividade biológica in vivo, porém, seus efeitos celulares são menos conhecidos. Geralmente quando muito curtas as $\beta$-glucanas são consideradas inativas para imunomodulação (BROWN; GORDON, 2003).

Muckosová, Babicek e Pospisil (2001) relataram que propriedades fisico-químicas e a habilidade de absorção das células intestinais são fatores que podem limitar a eficiência de agentes imunomodulatórios. Estes pesquisadores analisaram os efeitos imunoestimulantes da $\beta$-glucana e de dois derivados solúveis, a carboximetilglucana (CMG) e a sulfoetilglucana (SEG), obtidos de S. cerevisiae, administrados via oral e intraperitoneal para camundongos estimulados com lipopolissacarídeos (LPS). As duas vias de administração promoveram melhora significativa na produção de ácido nítrico e atividade de peroxidase das células aderentes peritoniais, porém, a via intraperitoneal foi mais eficaz.

Contudo, podem ocorrer efeitos adversos da administração intraperitoneal e intravenosa de $\beta$-glucanas de alto peso molecular, pois elas exibem afinidade para inúmeras ligações, além de atividades biológicas variadas (KUBALA et al., 2003). Conforme Chorvatovicová, Machová e Sandula (1996) a administração oral pode apresentar vantagens, embora o alto peso molecular e a estrutura complexa da $\beta$-glucana possam interferir na absorção pelo trato gastrointestinal. De acordo com Tsukada et al. (2003), a administração oral de $\beta$-glucana extraída de $S$. cerevisiae realça as funções dos linfócitos intraepiteliais do intestino e, portanto, é absorvida pelo mesmo. Em revisão sobre imunomoduladores, Tzianabos (2000) considerou que a dose, a via e o sincronismo de administração de um biomodulador podem realçar ou suprimir a resposta imune do hospedeiro.

\section{Atividade anticarcinogênica}

Anticarcinogênicos são substâncias capazes de impedir, retardar ou reduzir o surgimento, ou desenvolvimento de neoplasias (KURODA; HARA, 1999). Neste aspecto, a introdução de biomoduladores combinados com quimioterapia contribuiu significativamente para a terapia antineoplásica. Dentre os compostos conhecidos como imunomoduladores, $\beta$-glucanas extraídas da parede celular de fungos e leveduras vem 
sendo avaliadas por sua atividade antitumoral (MIADOKOVÁ et al., 2005).

Os estudos iniciais sobre o potencial uso da $\beta$ glucana contra o câncer foram realizados na década de 70. Já em 1979, Di Luzio et al. demonstraram que preparações de $\beta$-glucana de $S$. cerevisiae reduzem significativamente o crescimento de carcinomas mamários e melanomas. No mesmo estudo foi constatado aumento da sobrevida de camundongos com implante tumoral subcutâneo.

Atualmente, sabe-se que o mecanismo de ação antitumoral das $\beta$-glucanas, efetivo inclusive em situações de metástase, atua pela ativação e ampliação das diversas funções imunológicas do hospedeiro, constituindo-se de um tratamento que melhora a imunosobrevivência do hospedeiro ao tumor. Em adição, tem efeito antagônico à imunossupressão decorrente da quimioterapia e de tratamentos com irradiação (MOON et al., 2005). Os pesquisadores Xiao, Trincado e Murtagh (2004) relataram que os efeitos antitumorais da $\beta$-glucana são baseados principalmente, na habilidade de ativar leucócitos pelo estímulo da atividade fagocítica e produção de citocinas como o TNF- $\alpha$.

Em estudo de Hofer e Pospisil (1997), preparações de $\beta$-glucana de $S$. cerevisiae foram administradas a camundongos antes e depois de regimes sub-letais de irradiação gama. Os resultados revelaram estímulo da hematopoiese em todos os camundongos, inclusive no grupo controle. Segundo os pesquisadores o estímulo da produção de células sanguíneas na medula óssea, e consequentemente o aumento das células de defesa, conferiu proteção contra os efeitos da radiação e proporcionou aumento na sobrevida dos camundongos irradiados.

Inúmeras pesquisas realizadas, principalmente no Japão, comprovaram que a $\beta$-glucana de levedura realça os efeitos do tratamento quimioterápico e melhora a qualidade da sobrevida com pacientes de câncer tratados com radiação (KIM et al., 2006). No referido país, algumas $\beta$-glucanas licenciadas para o uso terapêutico vêm sendo utilizadas nas últimas décadas como adjuvantes na terapia antitumoral.

Derivados da $\beta$-glucana solúveis em água também apresentam potencial para a prevenção e terapia do câncer (MIADOKOVÁ et al., 2005). A administração de Carboximetilglucana (CMG) obtida de levedura durante o tratamento com ciclofosfamida, para o carcinoma de pulmão, contribuiu positivamente com significativo estímulo dos macrófagos (KOGAN et al., 2002). Conforme Miadoková et al. (2005) os derivados da $\beta$-glucana pertencem a uma das mais abundantes classes de biopolímeros que podem contribuir para a prevenção e terapia do câncer.

Demir et al. (2007) realizam estudo na Turkia, onde a $\beta$-glucana de $S$. cerevisiae foi administrada oralmente, durante 14 dias, para 23 mulheres com câncer de mama em estágio avançado. Foi constatada ativação de monócitos no sangue periférico, bem como estímulo da proliferação destes. Os exames clínicos não evidenciaram quaisquer efeitos colaterais decorrentes do uso via oral da $\beta$-glucana.

\section{Atividade antimutagênica}

Qualquer substância capaz de reduzir a freqüência de mutações espontâneas ou induzidas, independente do mecanismo de ação é considerada antimutagênica (WATERS et al., 1990). A atividade antimutagênica da $\beta$-glucana de $S$. cerevisiae vem sendo investigada, in vitro e in vivo, por diversos grupos de pesquisa. Compostos potencialmente mutagênicos como peróxido de hidrogênio, doxorrubicina e ciclofosfamida têm seus efeitos prejudiciais reduzidos pela administração deste polissacarídeo (CHORVATOVICOVÁ; MACHOVÁ; SANDULA, 1996; TOHAMY et al., 2003; SLAMENOVA et al, 2003; LIN et al., 2004).

Chorvatovicová, Machová e Sandula (1996) avaliaram os efeitos antimutagênicos da $\mathrm{CMG}$, obtida 
da $\beta$-glucana de $S$. cerevisiae, em camundongos utilizando a ciclofosfamina como agente indutor de danos ao DNA. A análise dos resultados demonstrou que a administração da $\mathrm{CMG}$, tanto via parenteral, como oral reduziu os efeitos clastogênicos da ciclofosfamina.

Estudos in vitro de Slamenová et al. (2003) comprovaram a eficácia da $\mathrm{CMG}$, SEG e carboximetilquitinaglucana (CMCG) na prevenção de lesões no DNA. A quantificação dos danos ao DNA em células pulmonares de hamsters V79 revelou maior eficiência da CMG no efeito preventivo. SEG e CMCG também foram eficientes, porém em menor grau. A prevenção, segundo os pesquisadores, ocorre pela reação da $\beta$-glucana com os radicais $\mathrm{OH}$-, liberados na biotransformação do peróxido de hidrogênio.

Estudo posterior ao de Slamenová, (MIADOKOVÁ et al., 2005) evidenciou que a CMG pode também reduzir os efeitos mutagênicos causados pela ofloxacina, exercendo bioproteção contra mutações pelo efeito antitóxico.

Recentemente, a pesquisa de Oliveira et al. (2007) comprovou o efeito da $\beta$-glucana de $S$. cerevisiae contra lesões no DNA, induzidas pelo metilmetano sulfonado, em células ovarianas de hamsters chineses. A $\beta$-glucana foi testada com pré, simultâneo e pós-tratamento ao agente mutagênico. Os efeitos quimiopreventivos da $\beta$-glucana foram observados em todas as situações de tratamento, com índices de redução de danos ao DNA variando de 35 a $57,3 \%$.

\section{Efeitos da $\beta$-glucana na dieta}

Os efeitos benéficos da ingestão continuada de $\beta$-glucana podem diminuir os riscos de doenças crônicas em humanos e animais. Em estudo sobre a atividade biológica de polissacarídeos da parede celular de $S$. cerevisiae na alimentação de suínos, Kogan e Kocher (2007) ressaltaram a importância do efeito protetor da $\beta$-glucana ao organismo pelo estímulo ao sistema imune comum de mucosas, que são áreas permanentemente expostas a patógenos.

A $\beta$-glucana tem se destacado entre os ingredientes utilizados para produção de alimentos funcionais (TOKUNAKA et al., 2002; RAMESH; THARANATHAN, 2003). Fragmentos obtidos a partir desta macromolécula, os oligossacarídeos, podem atuar como prebióticos estimulando seletivamente o crescimento de bactérias do trato intestinal, e servindo de fonte energética para a microflora benéfica (PRZEMYSLAW; PIOTR, 2003). Outros aspectos positivos, como redução dos níveis de colesterol e de açúcar no sangue, pela inclusão da $\beta$-glucana na dieta também já foram comprovados em humanos (KIM et al., 2006).

Nicolosi et al. (1999) estudaram os efeitos da ingestão de $\beta$-glucana de $S$. cerevisiae, adicionada ao suco de laranja, para os níveis de lipídios plasmáticos em homens obesos hipercolesterolêmicos. No estudo foi observada queda significativa no colesterol total e redução de $8 \%$ nos níveis séricos de colesterol LDL, após 8 semanas de consumo.

Wilson et al. (2004) avaliaram duas frações de $\beta$-glucana de cevada, sendo uma de baixo e outra de elevado peso molecular, para a diminuição de colesterol sérico utilizando hamsters com dieta hipercolesterolemica como modelo experimental. Os exames não evidenciaram diferenças na atividade das frações, sendo que ambas promoveram redução nos níveis de colesterol no soro. Semelhantes observações foram descritas por Matiazi (2005) na avaliação do efeito hipocolesterolêmico da $\beta$ glucana extraída de $S$. cerevisiae administrada a camundongos em dieta hipercolesterolêmica.

\section{Obtenção de $\boldsymbol{\beta}$-glucana de $S$. cerevisiae}

Desde a descoberta das propriedades benéficas da $\beta$-glucana para animais e humanos, inúmeros processos de isolamento e purificação deste polissacarídeo tem sido desenvolvidos(FREIMUND et al., 2003). 
A partir de linhagens de levedura a $\beta$-glucana pode ser obtida como material solúvel ou insolúvel. Preparações de $\beta$-glucana derivada de $S$. cerevisiae geralmente envolvem processos relativamente longos com diversas etapas de extração alcalina, ácida e orgânica e sucessivas lavagens (JAMAS; EASSON; OSTROFF , 1997). Três principais frações geralmente são obtidas na extração da parede celular de $S$. cerevisiae, sendo uma rica em manoproteínas com pouca $\beta$-glucana, outra contendo quitina e $\beta$-glucana insolúvel em álcali e uma terceira contendo $\beta$-glucana solúvel em álcali (MANNERS et al., 1973; FLEET; MANNERS, 1976). Uma etapa adicional no processamento de extração da $\beta$-glucana aplicada em alguns processamentos comerciais é o tratamento com ácido acético diluído para remover o glicogênio (BACON et al., 1969; JAMAS; EASSON; OSTROFF, 1997). Embora não seja um componente da parede celular e sim um material de reserva, o glicogênio pode ficar entre as cadeias de glucana e interferir no resultado da extração (THANARDKIT et al., 2002). Enzimas hidrolíticas seletivas também representam uma alternativa para obtenção dos componentes da parede celular (SHIBATA et al., 1986).

LEE et al. (2001) utilizaram passos seqüenciais de purificação na obtenção de $\beta$-glucanas de $S$. cerevisiae. Inicialmente com extração alcalina e posterior tratamento ácido obtiveram a glucanp1 contendo $0.8 \%$ de proteínas, que após cromatografia de alta eficiência (CLAE) resultou na glucan-p2 contendo $0.3 \%$ de proteínas. Através da cromatografia de afinidade em gel de agarose da glucan-p2 foi obtida a glucan-p3, livre de proteínas. As $\beta$-glucanas resultantes de cada passo da purificação foram avaliadas quanto à eficiência para a ativação de macrófagos. A glucan-p3 foi a mais eficaz dentre as três, evidenciando que as proteínas remanescentes do processo de extração interferem na bioatividade. Neste aspecto, Bohn e BeMiller (1995) comentaram que efeitos colaterais decorrentes do uso de extratos de $\beta$ glucana, geralmente, estão associados à presença de manoproteínas nas preparações extraídas.
O fato de ser insolúvel em água, e parte insolúvel em álcali dificulta a extração da $\beta$-glucana e, além disso, o rendimento nos processos tradicionais é pouco satisfatório (OHNO et al., 1999). Portanto, a possibilidade de simplificação e otimização dos processos de extração, sem o comprometimento das propriedades imunoestimulantes, traz inúmeros benefícios (SUPHANTHARIKA et al., 2003).

Ohno et al. (1999) obtiveram uma $\beta$-glucana de levedura, com solubilidade em solução diluída de hidróxido de sódio $(\mathrm{NaOH})$, utilizando oxidação com hipoclorito de sódio $(\mathrm{NaClO})$ e subseqüente extração com dimetil sulfóxido (DMSO). Conforme os pesquisadores, além do tempo reduzido e rendimento satisfatório, a extração manteve a atividade biológica da $\beta$-glucana. Posteriormente, o mesmo método foi empregado por Ishibashi et al. (2004) para extração de $\beta$-glucana de Aspergillus spp., e os resultados obtidos foram similares aos de Ohno et al. (1999).

Em seu estudo, Suphantharika et al. (2003) otimizaram a concentração de $\mathrm{NaOH}$, a temperatura e o tempo de extração para a obtenção da $\beta$-glucana da parede de levedura descartada em cervejaria. Após autólise das células de levedura a $50{ }^{\circ} \mathrm{C}$ por 24 horas, uma única etapa foi proposta para extração alcalina, tendo como condições ótimas: 5 volumes de $\mathrm{NaOH} 1 \mathrm{~N}$ a $90^{\circ} \mathrm{C}$ durante 1 hora. As propriedades imunoestimulantes da $\beta$-glucana foram comprovadas in vitro e in vivo em administração oral à camarões. Neste contexto, Jamas, Easson e Ostroff (1997) comentaram que no tratamento com álcali, em temperaturas elevadas, são hidrolizados e solubilizados proteínas celulares, mananas, frações solúveis de $\beta$-glucana, ácidos nucléicos e lipídeos polares, que ficam na fração sobrenadante, deixando as $\beta$-glucanas insolúveis na fração sólida. Conforme Thanardkit et al. (2002), as proteínas podem ser removidas na extração alcalina devido a alta concentração de $\mathrm{NaOH}$ e elevada temperatura , pois o uso soluções pouco concentradas e baixas temperaturas resultaria em preparações de $\beta$-glucana com conteúdo elevado de proteína residual. 
Outra pesquisa de otimização foi realizada por Matiazi (2005), para as condições de $\mathrm{pH}$ e temperatura na extração de $\beta$-glucana de $S$. cerevisiae oriunda de usina sucroalcoleira. Utilizando $\mathrm{NaOH}$ e ácido sulfúrico (H2SO4) para extração, os valores que permitiram o maior rendimento de $\beta(1-3) /(1-$ 6)glucana foram temperatura entre 68 e $78^{\circ} \mathrm{C} \mathrm{e} \mathrm{pH}$ entre 9,7 e 10,5 .

Com o objetivo de aumentar a especificidade e o rendimento da extração de $\beta$-glucana a partir de leveduras, métodos envolvendo etapas de digestão enzimática tem sido descritos (MAGNELLI; CIPOLLO; ABEIJON, 2002; LIU et al., 2006).

Um processo envolvendo extração com água quente, homogeneização, solvente orgânico e proteases para extração de $\beta$-glucana de $S$. cerevisiae foi apresentado por Liu et al. (2006). O processo aplica etapas "suaves" que não degradam as cadeias de $\beta$-glucana, mantendo sua estrutura original, além de permitir rendimento satisfatório e pureza. Outra consideração, não menos importante, é que o método proposto para a obtenção da $\beta$-glucana não utiliza produtos químicos agressivos ao meio ambiente.

A busca de novos métodos, que priorizam etapas pouco agressivas durante a extração da $\beta$-glucana, e possibilitam manter o máximo da estrutura original é de considerável importância. Além das etapas de extração, deve-se considerar também o processo empregado para secagem, onde o polímero também pode ser danificado. Hromádková et al. (2003) avaliaram a influência de três diferentes métodos de secagem nas propriedades físicas e imunomodulatórias da $\beta$-glucana de $S$. cerevisiae. As amostras foram secas através de liofilização, extração de solvente e spray drying, sendo posteriormente analisadas quanto às características reológicas da dispersão aquosa da $\beta$-glucana, estrutura, conformação e atividade imunomodulatória. O método de secagem afetou consideravelmente a microestrutura das partículas de $\beta$-glucana, que apresentaram diferenças nas propriedades físicas. Os resultados do estudo sugerem que estas diferenças influenciam significativamente também a atividade imunomodulatória, sendo que, a $\beta$-glucana seca em spray drying apresentou atividade duas vezes maior nos ensaios imunológicos, quando comparada às amostras provenientes dos demais métodos testados.

Alterações estruturais que proporcionam o aumento da solubilidade da $\beta$-glucana podem aumentar sua atividade imunomoduladora e antitumoral (BOHN; BeMILLER, 1995). Tokunaka et al. (2002) comentaram que a solubilidade afeta o efeito imunológico, pois exerce influência na ligação com o receptor. Sob este ponto de vista, Chorvatovicová, Machová e Sandula (1996) sugeriram que a solubilidade em água e a bioatividade das glucanas estão relacionadas ao seu grau de ramificação, sendo que cadeias altamente ramificadas são solúveis.

Diferentes métodos, como hidrólise ácida parcial e alcalina, digestão enzimática, fosforilação, sulfonilação, sulfatação, carboximetilação, irradiação de ultrasson e aminação podem ser aplicados na despolimerização de biopolímeros como a $\beta$-glucana, resultando em fragmentos solúveis e de menor massa molecular (SANDULA et al., 1999).

Nos últimos anos, inúmeras pesquisas vêm sendo realizadas para identificar características estruturais e biológicas de derivados da $\beta$-glucana solúveis em água, na expectativa de viabilizar seu uso clínico (SAKURAI et al., 1997; OHNO et al., 1999; MIURA et al., 2003; ISHIBASHI et al., 2004; MIADOKOVÁ et al., 2005; HARADA et al., 2006).

Apoio financeiro: Conselho Nacional de Desenvolvimento Científico e Tecnológico (CNPq) através de bolsa de doutorado. 


\section{Referências}

ADEREM, A.; ULEVITCH, R. J. Toll-like receptors in the induction of the innate immune response. Nature, London, v. 406, n. 6797, p. 782-787, 2000.

ARIIZUMI, K.; SHEN, G.-L.; SHIKANO, S.; XU, S.; RITTER, R.; KUMAMOTO, T.; EDELBAUM, D.; MORITA, A.; BERGSTRESSER, P. R.; TAKASHIMA, A. Identification of a novel, dendritic cell-associated molecule, dectin-1, by subtractive cDNA cloning. The Journal of Biological Chemistry, Bethesda, v.275, n. 26, p. 20157-20167, 2000.

BACON, J. S. D.; FARMER, V. C.; JONES, D.; TAYLOR, I. F. The glucan components of the cell wall of baker's yeast (Saccharomyces cerevisiae) considered in relation to its ultrastructure. Biochemical Journal, London, v. 114, n. 3, p. 557-567, 1969.

BALLOY, V.; SI-TAHAR, M.; TAKEUCHI, O.; PHILIPPE, B.; NAHORI, M.-A.; TANGUY, M.; HUERRE, M.; AKIRA, S.; LATGÉ, J.-P.; CHIGNARD, M. Involvement of Toll-like receptor 2 in experimental invasive pulmonary aspergillosis. Infection and Immunity, Washington, v. 73, n. 9, p. 5420-5425, 2005.

BATTLE, J.; HA, T.; LI, C.; DELLA BEFFA, V.; RICE, P.; KALBFLEISCH, J.; BROWDER, W.; WILLIAMS, D. Ligant binding to the (1-3)- $\beta$-D-glucan receptor stimulates NFkB activation, but not apoptosis in U937 cells. Biochemical and Biophysical Research Communications, Orlando, v. 249, n. 2, p. 499-504, 1998.

BEHALL, K. M.; SCHOLFIELD, D. J.; HALLFRISCH, J. G.; LILJEBERG-ELMSTÅHL, H. G. M. Consumption of both resistant starch and $\beta$-glucan improves postprandial -plasma glucose and insulin in women. Diabetes Care, Alexandria, v. 29, n. 5, p. 976-981, 2006.

BERNER, M.D.; SURA, M.E.;ALVES, B. N.; HUNTERJr. K, W. IFN-gamma primes macrophages for enhanced TNF-alpha expression in response to stimulatory and non-stimulatory amounts of microparticulate $\beta$-glucan. Immunology Letters, Amsterdam, v. 98, n. 1, p. 115-122, 2005.

BHATTY, R. S. Extraction and enrichment (1-3)(1-4)$\beta$-Dglucan from barley and oat brans. Cereal Chemistry, Saint Paul, v. 70, n. 1, p. 73-77, 1993.

BOHN, J. A.; BeMILLER, J. M. (1-3)- $\beta-D-G l u c a n s$ as biological response modifiers: a review of structurefunctional activity relationships. Carbohydrate Polymers, Barking, v. 28, n. 1, p. 3-14, 1995.

BROWN, G. D.; GORDON, S. A new receptor for $\beta$ glucans. Nature, London, v. 413, n. 1, p. 36-36, 2001.
Fungal $\beta$-glucans and mammalian immunity. Immunity, Cambridge, v. 19, n. 3, p. 311-315, 2003.

Immune recognition of fungal. Cellular Microbiology, Oxford, v. 7, n. 4, p. 471-479, 2005.

CABIB, E.; DRGANOVÁ, J.; DRGON, T. Role of small $G$ proteins in yeast cell polarization and wall biosynthesis. Annual Review of Biochemistry, Palo Alto, v. 67, p. 307333, 1998.

CHORVATOVICOVÁ, D.; MACHOVÁ, E.; SANDULA, J. Effect of ultrasonicated carboxymethylglucan on cyclophosphamide induced mutagenicity. Mutation Research, Amsterdam, v. 371, n. 1-2, p. 115-120, 1996.

CID,V. J.; DURAN, A.; DEL REY, F.; SNYDER, M. P.; NOMBELA, C.; SANCHEZ, M. Molecular basis of cell integrity and morphogenesis in S. cerevisiae. Microbiology Reviews, Washington, v. 59, p. 345-386, 1995.

De NOBEL, J. G.; KLIS, F. M.; PRIEM, J.; MUNNIK, T.; Van Den ENDE, H. The glucanase-soluble mannoproteins limit cell wall porosity in Saccharomyces cerevisiae. Yeast, Chichester, v. 6, n. 6, p. 491-499, 1990.

De NOBEL, J. G.; BARNETT, J. A. Passage of molecules through yeast cell walls: a brief essay-review. Yeast, Chichester, v. 7, n. 4, p. 313-323, 1991.

DEMIR, G.; KLEIN, H. O.; MANDEL-MOLINAS, $\mathrm{N}$; TUZUNER, N. $\beta$-glucan induces proliferation and activation of monocytes in peripheral blood of patients with advanced breast cancer. International Immunopharmacology, Amsterdam, v. 7, n. 1, p. 113116, 2007.

DiCARLO, F. J.; FIORE, J. V. On the composition of zymosan. Science, New York, v. 127, n., p. 756-157, 1958.

Di LUZIO, N. R.; WILLIAMS, D. L.; McNAMEE, R. B.; EDWARDS, B. F.; KITAHAMA, A. Compartive tumor-inhibitory and anti-bacterial activity of soluble and particulate glucan. International Journal of Cancer, New York, v. 24, n. 6, p. 773-779, 1979.

Di RENZO, L.; YEFENOF, E.; KLEIN, E. The function of human NK cells is enhanced by $\beta$-glucan, a ligand of CR3 (CD11b/CD18). European Journal of Immunology, Weinheim, v. 21, n. 7, p. 1755-1758, 1991.

DIJKGRAAF, G. J. P.; LI, H.; BUSSEY, H. Cell- $\beta$ glucans of Saccharomyces cervisiae. In: VANDAMME, E. J.; De BAETS, S.; STEINBUCHEL, A. (Eds.). Biopolymers. Weinheim: Wiley-VCH Verlag, 2002. v. 6, p. 179-213. 
DURAN, A.; NOBLEGA, C. Fungal cell wall biogenesis: building a dynamic interface with the environment. Microbiology, Washington, v. 150, n. 10, p. 3099-3103, 2004.

FIRON, A.; LESAGE, G.; BUSSEY, H. Integrative studies put cell wall synthesis on the yeast functional map. Current Opinion in Microbiology, Oxford, v. 7, n. 6, p. 617-623, 2004.

FITZPATRICK, F.W.; DICARLO, F. J. Zymosan. Annals of the New York Academy of Sciences, New York, v. 118, n. 4, p. 233-262, 1964.

FLEET, G. H. Composition and structure of yeast cell walls. Current Topics in Medical Mycology, New York, v. 1, n. 1, p. 24-24, 1985.

FLEET, G. H.; MANNERS, D. J. Isolation and composition of an alkali-soluble glucan from the cell walls of Saccharomyces cerevisiae. Journal of General Microbiology, London, v. 94, n., p. 180-192, 1976.

FREIMUND, S.; SAUTER, M.; KÄPPELI, O.; DUTLER, $H$. A new non-degrading isolation process for $1,3-\beta$-Dglucan of high purity from baker's yeast Saccharomyces cerevisiae. Carbohydrate Polymers, Barking, v. 54, n. 2, p. 159-171, 2003.

GANTNER, B. N.; SIMMONS, R. M.; CANAVERA, S. J.; AKIRA, S.; UNDERHILL, D. M. Collaborative induction of inflammatory responses by Dectin-1 and Toll-like receptor 2. Journal of Experimental Medicine, New York, v. 197, n. 9, p. 1107-1117, 2003.

HA, C.-H.; LIM, K.-H.; KIM, Y.-T.; LIM, S.-T.; KIM, C.-W.; CHANG, H. -I. Analysis of alkali- soluble glucan produced by Saccharomyces cerevisiae wild-type and mutants. Applied Microbiology and Biotechnology, Berlin, v. 58, n. 3, p. 370-377, 2002.

HAHN, P.Y.; EVANS, S. E.; KOTTOM, T. J.; STANDING, J. E.; PAGANO, R. E.; LIMPER, A.H. Pneumocystis carinii cell wall $\beta$-glucan induces release of macrophage inflammatory protein-2 from alveolar epithelial cells via a lactosylceramide-mediated mechanism. Journal of Biological Chemistry, Bethesda, v. 278, n. 3, p. 2043-2050, 2003.

HARADA, T.; KAWAMINAMI, H.; MIURA, N. N.; ADACHI, Y.; NAKAJIMA, M.; YADOMAE, T.; OHNO, N. Mechanism of enhanced hematopoietic response by soluble $\beta$-glucan SCG in cyclophosphamidetreated mice. Microbiology and Immunology, Tokyo, v. 50, n. 9, p. 687-700, 2006.

HARTLAND, R. P.; VERMEULEN, C. A.; SIETSMA, J. H., WESSELS, J. G. H.; KLIS, F. M. The linkage of (1-3)- $\beta$-glucan to chiting during cell wall assembly in
Saccharomyces cerevisiae. Yeast, Chichester, v. 10, n. 12, p. 1591-1599, 1994.

HASSID, W. Z.; JOSLYN, M. A.; McCREADY, R. M. The molecular constitution of insoluble polysaccharide from yeast. Journal of the American Chemistry Society, Columbus, v. 63, n. 1, p. 295-298, 1941.

HERRE, J.;MARSHALL,A.J.; CARON,E.;EDWARDS, A. D.; WILLIAMS, D. L.; SCHWEIGHOFFER, E.; SCHWEIGHOFFER, E.; TYBULEWICZ, V.; SOUSA, C. R.; HERRE, J.; GORDON, S.; BROWN, G. D. Dectin- 1 and its role in the recognition of $\beta$-glucans by macrophages. Molecular Immunology, Elmsford, v. 40, n. 12, p. 869-876, 2004.

HIDA, S.; NAGI-MIURA, N.; ADACHI, Y.; ONHO, N. $\beta$-glucan derived from zymosan acts as an adjuvant for collagen-induced arthritis. Microbiology and Immunology, Tokyo, v. 50, n. 6, p. 453-461, 2006.

HOFER, M.; POSPISIL, M. Glucan as stimulator of hematopoiesis in normal and gamma-irradiated mice. A survey of the authors'results. International Journal of Immunopharmacology, Oxford, v. 19, n. 9, p. 607-609, 1997.

HOLBROOK, T. W.; COOK, J. A.; PARKER, B. W. Immunization against Leishmania dovavani: glucana as an adjuvant with killed promastigotes. American Journal of Tropical Medicine and Hygiene, Mclean, v. 30, n. 4, p. 762-768, 1981.

HROMÁDKOVÁ, K.; EBRINGEROVÁ, A.; SASINKOVÁ, V.; SANDULA, J.; HRIBALOVÁ, V.; OMELKOVÁ, J. Influence of the drying method on the physical properties and immunomodulatory activity of the particulate (1-3)- $\beta$-D-glucan from Saccharomyces cerevisiae. Carbohydrate Polymers, Barking, v. 51, n. 1, p. 9-15, 2003.

ISHIBASHI, K.-I, MIURA, N. N.; ADACHI, Y; TAMURA, H.; TANAKA, S.; OHNO, N. The solubilization and biological activities of Aspergillus $\beta$-(1-3)-D-glucan. FEMS Immunology and Medical Microbiology, Amsterdam, v. 42, n. 2, p. 155-166, 2004.

JAMAS, S.; EASSON, D. D.; OSTROFF, G. R. Glucan preparation. US Patent 5622939, 22 Apr. 1997.

JUNG, K.; HA, Y.; HA, S.-K.; HAN, D. U.; KIM, D.-W, MOON, K. W.; CHAE, C. Antiviral effect of Saccharomyces cerevisiae $\beta$-glucan to swine influenza by increased production of interferon- $\gamma$ and nitric oxide. Journal of Veterinary Medicine, Chicago, v. 51, n. 2, p. 72-76, 2004. 
KAPTEYN, J. C.; RAM, A. F.; GROOS, E. M.; KOLLAR, R.; MONTIJN, R. C.; VAN DEN ENDE, H.; LLOBELL, A. A.; CABIB, E.; KLIS, F. M. Altered extent of cross-linking of $\beta 1,6$-glucosylated mannoproteins to chitin in Saccharomyces cerevisiae mutants with reduced cell wall $\beta 1,3$ glucan content. Journal of Bacteriology, Washington, v. 179, n. 20, p. 6279-6284, 1997.

KAPTEYN, J. C.; VAN OEN ENOE, H.; KLIS, F. M. The contribution of cell wall proteins to the organization of the yeast cell wall. Biochimica et Biophysica Acta, Amsterdam, v. 1462, n. 2, p. 373-383, 1999.

KARREMAN, R. J.; DAGUE, E.; GABORIAUD, F.; QUILÈS, F.; DUVAL, J. F. L.; LINDSEY, G. G. The stress response protein Hsp12p increases the flexibility of the yeast Saccharomyces cerevisiae cell wall. Biochimica et Biophysica Acta, Amsterdam, v. 1774, n. 1, p. 131137, 2007.

KHALIKOVA, T. A.; ZHANAEVA, S. YA.; KOROLENKO, T. A.; KALEDIN, V. I.; KOGAN, G. Regulation of activity of cathepsins B, L, and D in murine lymphosarcoma model at a combined treatment with cyclophosphamide and yeast polysaccharide. Cancer Letters, Amsterdam, v. 223, n. 1, p. 77-83, 2005.

KIM, K. S.; YUN, H. S. Production of soluble $\beta$-glucan from the cell wall of Saccharomyces cerevisiae. Enzyme and Microbial Technology, New York, v. 39, n. 3, p. 496-500, 2006.

KIM, S. Y.; SONG, H. J.; LEE, Y. Y.; CHO, K.-H.; $\mathrm{ROH}, \mathrm{Y}$. K. Biomedical issues of dietary fiber $\beta$-glucan. Journal Korean of Medical Science, Seoul, v. 21, n. 10, p. 781-789, 2006.

KLIS, F. M. Review: cell wall assembly in yeast. Yeast, Chichester, v. 10, n. 7, p. 851-869, 1994.

KLIS, F. M.; MOL, P.; HELLINGWERF, K.; BRUL, S. Dynamics of cell wall structure in Saccharomyces cerevisiae. FEMS Microbiology Reviews, Amsterdam, v. 26, n. 3, p. 239-256, 2002.

KO, Y.-T.; LIN, Y.-L. 1,3- $\beta$-Glucan quantification by a fluorescence microassay and analysis of its distribution in foods. Journal of Agricultural and Food Chemistry, Easton, v. 52, n. 11, p. 3313-3318, 2004.

KOGAN, G. (1-3)(1-6)ß-D-Glucans of yeasts and fungi and their biological activity. Studies in Natural Products Chemistry, Amsterdam, v. 23, Part D, p. 107-152, 2000.

KOGAN, G.; KOCHER, A. Role of yeast cell wall polysaccharides in pig nutrition and health protection. Livestock Science, Amsterdam, v. 109, n. 1-3, p. 161165, 2007. doi:10.1016/j.livsci.2007.01.134.
KOGAN, G.; SANDULA, J.; KOROLENKO, T. A.; FALAMEEVA, O. V.; POTERYAEVA, O. N.; ZHANAEVA, S. YA.; LEVINA, O. A.; FILATOVA, T. G.; KALEDIN, V. I. Increased efficiency of Lewis lung carcinoma chemotherapy with a macrophage stimulator: yeast carboxymethyl glucan. International Immunopharmacology, Amsterdam, v. 2, n. 6, p. 775781, 2002.

KOLLÁR, R.; REINHOLD, B. B.; PETRAKOVA, E.; YEH, H. J.; ASHWELL, G.; DRGONOVA,, J.; KAPTEYN, J. C.; KLIS, F. M.; CABIB, E. Architecture of the Yeast Cell Wall: $\beta(1-6)$-glucan interconnects mannoprotein, $\beta(1-3)$-glucan, and chitin. The Journal of Biological Chemistry, Bethesda, v. 272, n. 28, p. 1776217775, 1997.

KOPECKÁ, M.; PHAFF, H. J.; FLEET, G. H. Demonstration of a fibrillar component in the cell wall of the yeast Saccharomyces cerevisiae and its chemical nature. The journal of Cell Biology, New York, v. 62, n. 1, p. 66-76, 1974.

KRAINER, E.; STARK, R. E.; NAIDER, F.; ALAGRAMAM, K.; BECKER, J. M. Direct observation of cell wall glucans in whole cells of Saccharomyces cerevisiae by magic-angle spinning 13C-NMR. Biopolymers, New York, v. 34, n. 12, p. 1627-1635, 1994.

KUBALA， L.; RUZICKOVA， J.; NICKOVA， K.; SANDULA, J.; CIZ, M.; LOJEK, A. The effect of (1$3)-\beta$-D-glucans, carboxymethylglucan and schizophyllan on human leukocytes in vitro. Carbohydrate Research, Amsterdam, v. 338, n. 24, p. 2835-/2840, 2003.

KULICKE, W.-M.; LETTAU, A. L.; THIELKING, H. Correlation between immunological activity, molar mass, and molecular structure of different (1-3)- $\beta$-D-glucans. Carbohydrate Research, Amsterdam, v. 297, n. 2, p. 135143, 1997.

KURODA, Y.; HARA, Y. Antimutagenic and anticarcinogenic activity of tea polyphenols. Mutation Research, Amsterdam, v. 436, n. 1, p. 69-97, 1999.

LEE, D.-Y.; JI, I.-H.; CHANG, H.-I.; KIM, C. H. Highlevel TNF- $\alpha$ on secretion and macrophage activity with soluble $\beta$-glucans from Saccharomyces cerevisiae. Bioscience, Biotechnology and Biochemistry, Tokyo, v. 66, n. 2, p. 233-238, 2002.

LEE, J.-N.; LEE, D.-Y.; JI, I.-H.; KIM, G.-E.; KIM, H. N.; SOHN, J.; KIM, S.; KIM, C. W. Purification of Soluble $\beta$-Glucan with Immune-enhancing activity from the cell wall of yeast. Bioscience, Biotechnology and Biochemistry, Tokyo, v. 65, n. 4, p .837-841, 2001. 
LIANG, J.; MELICAN, D.; CAFRO, L.; PALACE, G.; FISETTE, L.; ARMSTRONG, R.; PATCHEN, M. L. Enhanced clearance of a multiple antibiotic resistant Staphylococcus aureus in rats treated with PGG-glucan is associated with increased leukocyte counts and increased neutrophil oxidative burst activity. International Journal of Immunopharmacology, New York, v. 20, n. 11, p. 595-614, 1998.

LIN, H.; SHE, Y.; CASSILETH, B.; SIROTNAK, F.; RUNDLES, S.C.Maitakebeta-glucanMD-fractionenhances bone marrow colony formation and reduces doxorubicin toxicity in vitro. International Immunopharmacology, Amsterdam, v. 4, n. 1, p. 91-99, 2004.

LIPKE, P. N.; OVALLE, R. Cell Wall Architecture in Yeast: New Structure and New Challenges. Journal of Bacteriology, Washington, v. 180, n. 15, p. 3735-3740, 1998.

LIU, X.-Y.; WANG, Q.; CUI, S. W.; LIU, H.-Z. A new isolation method of $\beta$-D-glucans from spent yeast Saccharomyces cerevisiae. Food Hydrocolloids, Oxford, v. 22, n. 2, p. 239-247, 2006. doi:10.1016/ j.foodhyd.2006.11.008.

LUHM, J.; LANGENKAMP, U.; HENSEL, J.; FROHN, C.; BRAND, J. M.; HENNIG, H.; RINK, L.; KORITKE, P.; WITTKOPF, N.; WILLIAMS, D. L.; MUELLER, A. $\beta$ - $(1 \rightarrow 3)$-D-glucan modulates DNA binding of nuclear factors $\kappa \mathrm{B}, \mathrm{AT}$ and IL-6 leading to an anti- inflammatory shift of the IL-1 $/ / \mathrm{IL}-1$ receptor antagonist ratio. BMC Immunology, London, v. 7, n. 1, p. 5, 2006. doi: 10.1186/1471-2172-7-5.

MAGNELLI, P.; CIPOLLO, J. F.; ABEIJON, A. A refined method for the determination of Saccharomyces cerevisiae cell wall composition and $\beta$-1,6-glucan fine structure analytical. Biochemistry, Washington, v. 301, n. 1, p. 136-150, 2002.

MANNERS, D. J.; MASSON, A. J.; PATTERSON, J. A.; BJORNDAL, H.; LINDBERG, B. The structure of a $\beta(1-6)$ - D- glucan from yeast cell walls. Biochemistry Journal, Washington, v.135, n. 1, p.31-36, 1973.

MATIAZI, H. J. Otimização de Extração de glucana da parede celular de Sacharomyces cerevisiae e sua ação hipocolesterolemica e antimutagênica. 2005. Tese. (Doutorado em Ciência de Alimentos) - Universidade Estadual de Londrina, Paraná.

MEIRA, D. A.; PEREIRA, P. C. M.; MARCONDESMACHADO, J.; MENDES, R. P.; BARRAVIERA, B.; PELLEGRINO, J. R. J.; REZKALLAH-IWASSO, M. T.; PERAÇOLI, M. T. S.; CASTILHO, L. M.; THOMZAINI, I.; SILVA, C. L.; FOSS, N. T.; CURRI, P. R. The use of glucan as immunostimulant in the treatment of paracoccidioidomycosis. American Journal of Tropical Medicine and Hygiene, Mclean, v. 55, n. 5, p. 496-503, 1996.

MIADOKOVÁ, E.; SVIDOVÁ, S.; VLCKOVÁ, V.; DÚHOVÁ, V.; PRAZMÁRIOVÁ, E.; TOTHOVÁ, K.; NAĎOVÁ, S.; KOGAN, G.; RAUKO, P. The role of natural biopolymers in genotoxicity of mutagens/ carcinogens elimination. Biomedical Papers of the Medical Faculty of the University Palacky, Olomouc, v. 149, n, p. 493-496, 2005.

MIURA, N. N.; ADACHI, Y.; YADOMAE, T.; TAMURA, H.; TANAKA, S.; OHNO, N. Structure and biological activies of $\beta$-glucans from yeast and mycelial forms of Candida albicans. Microbiology and Immunology, Tokyo, v. 47, n. 3, p. 173-182, 2003.

MIURA, N. N.; OHNO, N.; ADACHI, Y.; WATANABE, M.; TAMURA, H.; TANAKA, S.; YADOMAE, T. Gradual solubilization of Candida cell wall $\beta$-glucan by oxidative degradation in mice. FEMS Immunology and Medical Microbiology, Amsterdam, v. 21, n. 2, p. 123129, 1998.

MOON, S.-H.; HEO, J.-C.; FINE, R.-L.; KIM, H.-M.; KIM, S.-U.; YOON, B.-D.; LEE, S.-H. BRD-glucan exhibits potent immunochemotherapeutic activity in vitro and in vivo. International Journal of Oncology, Athens, v. 26, n. 2, p. 395-404, 2005.

MORRIS, G. J.; WINTERS, L.; COULSON, G. E.; CLARKE, K. J. Effect on osmotic stress on the ultrastructure and viability of the yeast Saccharomyces cerevisiae. Journal of General Microbiology, London, v. 129, n., p. 2023-2034, 1986.

MUCKSOVÁ, J.; BABÍCEK, K.; POSPISIL, M. Particulate 1,3- $\beta$-D-Glucan, Carboxymethylglucan and Sulfoethylglucan - Influence of their oral or intraperitoneal administration on immunological respondence of mice. Folia Microbiologica, Praha, v. 46, n. 6, p. 559-563, 2001.

NICHOLAS, J. C.; SHAUN, R. M. C. Production of chemokines in vivo in response to microbial stimulation. The Journal of Immunology, Baltimore, v. 166, n. 8, p. 5176-5182, 2001.

NICOLOSI, R.; BELL, S. J.; BISTRIAN, B. R.; GREENBERG, I.; FORSE, R. A.; BLACKBURN, G. L. Plasma lipid changes after supplementation with $\beta$ glucan fiber from yeast. American Journal of Clinical Nutrition, New York, v. 70, n. 2, p. 208-212, 1999.

NONO, I.; OHNO, N.; MASUDA, A.; OIKAWA, S.; YADOMAE, T. Oxidative degradation of an antitumor (1-3)- $\beta$-D-glucan, grifolan. Journal of Pharmacobiodynamics, Tokyo, v. 14, n. 1, p. 9-19, 1991. 
OHATA, A.; USAMI, M.; HORIUCHI, T.; NAGASAWA, K.; KINOSHITA, K. Release of (1-3)- $\beta$-D-glucan from depth-type membrane filters and their in vitro effects on proinflammatory cytokine production. Artificial Organs, Cleveland, v. 27, n. 8, p. 728-735, 2003.

OHNO, N.; HASHIMOTO, T.; ADACHI, Y.; YADOMAE, T. Conformation dependency of nitric oxide synthesis of murine peritoneal macrophages by (1$3)-\beta$-glucans in vitro. Immunology Letters, Amsterdam, v. 53, n. 2-3, p. 157-163, 1996.

OHNO, N.; UCHIYAMA, M.; TSUZUKI, A.; TOKUNAKA, K.; MIURA, N. N.; ADACHI, Y.; AIZAWA, M. W.; TAMURA, H.; TANAKA, S.; YADOMAE, T. Solubilization of yeast cell-wall $\beta-$ (1-3)-D-glucan by sodium hypochlorite oxidation and dimethyl sulfoxide extraction. Carbohydrate Research, Amsterdam, v. 316, n. 1, p. 161-172, 1999.

OLIVEIRA, R. J.; MATUO, R.; DA SILVA A. F.; MATIAZI, H. J.; MANTOVANI, M. S.; RIBEIRO, L. R. Protective effect of $\beta$-glucan extracted from Saccharomyces cerevisiae, against DNA damage and cytotoxicity in wild-type (k1) and repair-deficient (xrs5) CHO cells.Toxicology in Vitro, Oxford, v. 21, n. 1, p. 41-52, 2007.

PEISER, L.; MUKHOPADHYAY, S.; GORDON, S. Scavenger receptors in innate immunity. Current Opinion in Immunology, London, v. 14, n. 1, p. 123-128, 2002.

PELOSI, L.; IMAI, T.; CHANZY, H.; HEUX, L.; BUHLER, E.; BULONE, B. Structural and Morphological Diversity of (1-3)- $\beta$-D-Glucans Synthesized in vitro by enzymes from Saprolegnia monoica. Comparison with a corresponding in vitro product from blackberry (Rubus fruticosus). Biochemistry, Washington, v. 42, n. 20, p. 6264-6274, 2003.

PILLEMER, L.; LUM, L.; LEPOW, I. H.; WURZ, L.; TODD, E. W. The properdin system and immunity : III The zymosan assay of properdin. The Journal of Experimental Medicine, New York, v. 103, n. 1, p. 1-13, 1956.

PRZEMYSLAW, J. T.; PIOTR, T. Probiotics and Prebiotics. Cereal Chemistry, Saint Paul, v. 80, n. 2, p. 113-117, 2003.

RAMESH, H. P.; THARANATHAN, R. N. Carbohydrates - The renewable raw materials of high biotechnological value. Critical Reviews in Biotechnology, Boca Raton, v. 23, n. 2, p. 149-173, 2003.

REES, D. A.; MORRIS, E. R.; THOM, D.; MADDEN, J. K. Shapes and interactions of carbohydrate chains. In: ASPINALL, G.O. (Ed.). The Polysaccharides. New York: Academic Press, 1982. v. 1, p. 196-290.
REID, D. M.; MONTOYA, M.; TAYLOR, P. R.; BORROW, P.; GORDON, S.; BROWN, G. D.; WONG, S. Y. Expression of the $\beta$-glucan receptor, Dectin- 1 , on murine leukocytes in situ correlates with its function in pathogen recognition and reveals potential roles in leukocyte interactions. Journal of Leukocyte Biology, New York, v. 76, n. 1, p. 86-94, 2004.

REYNOLDS, J. A.; KASTELLO, M. D.; HARRIGTON, D. G.; CRABS, C. L.; PETERS, C. J.; JEMSKI, J. V.; SCOTT, G. H.; DI LUZIO, N. R. Glucan-induced enhancement of host resistance to selected infectious diseases. Infection and Immunity, Washington, v. 30, n. 1, p. 51-57, 1980.

RICE, P. J.; KELLEY, J. L.; KOGAN, G.; ENSLEY, H. E.; KALBFLEISCH, J. H.; BROWDER, I. W.; WILLIAMS, D. L. Human monocyte scavenger receptors are pattern recognition receptors for (1-3)- $\beta$-D-glucans. Journal of Leukocyte Biology, New York, v. 72, n. 1, p. 140-146, 2002.

ROEMER, T.; PARAVICINI, G.; PAYTON, M. A.; BUSSEY, H. Characterization of the yeast (1-6)- $\beta$-glucan biosynthetic components, Kre6p and Skn1p, and genetic interactions between the PKC1 pathway and extracellular matrix assembly. The Journal of Cell Biology, New York, v. 127, n. 2, p. 567-579, 1994.

ROSS, G. D.; VETVICKA, V.; YAN, J.; XIA, Y.; VETVICKOVA, J. Therapeutic intervention with complement and $\beta$-glucan in cancer. Immunopharmacology, New York, v. 42, n. 1, p. 61-74, 1999.

SAKURAI, T.; KAISE, T.; YADOMAE, T.; MATSUBARA, C. Different role of serum components and cytokines on alveolar macrophage activation by soluble fungal (1-3) $\beta$-D-glucan. European Journal of Pharmacology, Amsterdam, v. 334, n. 2-3, p. 255-263, 1997.

SANDULA, J.; KOGAN, G.; KACURAKOVÁ, M.; MACHOVÁ, E. Microbial (1-3)- $\beta$-D-glucans, their preparation, physico-chemical characterization and immunomodulatory activity. Carbohydrate Polymers, Barking, v. 38, n. 3, p. 247-253, 1999.

SHAHINIAN, S.; BUSSEY, H. $\beta$-1,6-Glucan synthesis in Saccharomyces cerevisiae. Molecular Microbiology, Salem, v. 35, n. 3, p. 477-489, 2000.

SHIBATA, N.; KOBAYASHI, H.; TOJO, M.; SUZUK, S. Characterization of phosphomannan-protein complexes isolated from viable cells of yeast and mycelial forms of Candida albicans NIH B-792 strain by the action of zymolyase-100T. Archives of Biochemistry and Biophysic, New York, v. 251, n. 2, p. 697-708, 1986. 
SIMONS, J. F.; EBERSOLD, M.; HELENIUS, A. Cell wall 1,6- $\beta$-glucan synthesis in Saccharomyces cerevisiae depends on ER glucosidases I and II, and the molecular chaperone BiP/Kar2p. The EMBO Journal, Oxford, v. 17, n. 2, p. 396-405, 1998.

SLAMENOVÁ, D.; LÁAJ, J.; KRIZKOVÁ, L.; KOGAN, G.; SANDULA, J.; BRESGEN, N.; ECKL, P. Protective effects of fungal (1 - 3)- $\beta$-D-glucan derivatives against oxidative DNA lesions in V79 hamster lung cells. Cancer Letters, Amsterdam, v. 198, n. 2, p. 153-160, 2003.

SMITH,A.E.; ZHANG,Z.; THOMAS, C.R.; MOXHAM, K. E.; MIDDELBERG, A. P. The mechanical properties of Saccharomyces cerevisiae. Proceedings of the National Academy of Sciences of the United States of America, Washington, v. 97, n. 18, p. 9871-9874, 2000.

SOLTÝS, J.; QUINN, M. T. Modulation of endotoxinand enterotoxin- induced cytokine release by in vivo treatment with $\beta$-(1,6)-branched $\beta$-(1,3)-glucan. Infection and Immunity, Washington, v. 67, n. 1, p. 244-252, 1999.

STEELE, C.; MARRERO, L.; SWAIN, S.; HARMSEN, A. G.; ZHENG, M.; BROWN, G. D.; GORDON, S.; SHELLITO, J. E.; KOLLS, J. K. Alveolar macrophagemediated killing of Pneumocystis carinii f. sp. muris involves molecular recognition by the dectin- $1 \beta$-glucan receptor. The Journal of Experimental Medicine, New York, v. 198, n. 11, p. 1677-1688, 2003.

STRATFORD, M. Another brick in the wall? Recent developments concerning the yeast cell envelope. Yeast, Chichester, v. 10, n. 13, p. 1741-1752, 1994.

SUDA, M.; OHNO, N.; ADACHI, Y.; YADOMAE, $\mathrm{T}$. Tissue distribution of intraperitoneally administered (1-3)- $\beta$-D-glucan (SSG), a highly branched antitumor glucan, in mice. Journal of Pharmacobio-dynamics, Tokyo, v. 15, n. 8, p. 417-426, 1992.

SUDA, M.; OHNO, N.; HASHIMOTO, T.; KOIZUMI, K.; ADACHI, Y.; YADOMAE, T. Kupffer cells play important roles in the metabolic degradation of a soluble anti-tumor (1-3)- $\beta$-D-glucan, SSG, in mice. FEMS Immunology and Medical Microbiology, Amsterdam, v. 15, n. 2-3, p. 93-100, 1996.

SUPHANTHARIKA, M.; KHUNRAE, P.; THANARDKIT, P.; VERDUYN, C. Preparation of spent brewer's yeast $\beta$-glucans with a potential application as an immunostimulant for black tiger shrimp, Penaeus monodon. Bioresource Technology, Essex, v. 88, n. 1, p. 55-60, 2003.

SUZUKI, M.; IGARASHI, R.; SEKIYA, M.; UTSUGI, T.; MORISHITA, S.; YUKAWA, M.; OHYA, Y. Dynactin is involved in a checkpoint to monitor cell wall synthesis in Saccharomyces cerevisiae. Nature Cell Biology, v. 6, p. 861-871, 2004.

TAKAHASHI, H.; OHNO, N.; ADACHI, Y.; YADOMAE, T. Association of immunological disorders in lethal side effect of NSAIDs on $\beta$-glucan-administered mice. FEMS Immunology and Medical Microbiology, Amsterdam, v. 31, n. 1, p. 1-14, 2001.

TAYLOR, P. R.; BROWN, G. D.; REID, D. M.; WILLMENT, J.A.; MARTINEZ-POMARES, L.; GORDON, S.; WONG, S. Y. The $\beta$-glucan receptor, dectin-1, is predominantly expressed on the surface of cells of the monocyte/macrophage and neutrophil lineages. Journal of Immunology, Baltimore, v. 169, n. 7, p. 3876-3882, 2002.

THANARDKIT, P.; $\quad$ KHUNRAE, P.; SUPHANTHARIKA, M.; VERDUYN, C. Glucan from spent brewer's yeast: preparation, analysis and use as a potential immunostimulant in shrimp feed. World Journal of Microbiology and Biotechnology, Oxford, v. 18, n. 6, p. 527-539, 2002.

THORNTON, B. P.; VETVICKA, V.; PITMAN, M.; GOLDMAN, R. C.; ROSS, G. D. Analysis of the sugar specificity and molecular location of the $\beta$-glucan-binding lectin site of complement receptor type 3 (CD11b/CD18). Journal of Immunology, Baltimore, v. 156, n. 3, p. 12351246, 1996.

TOHAMY, A. A.; EL-GHOR, A. A.; EL-NAHAS, S. M.; NOSHY, M. M. $\beta$-Glucan inhibits the genotoxicity of cyclophosphamide, adramycin and cisplatin, Mutation Research, Amsterdam, v. 541, n. 1, p. 45-53, 2003.

TOKUNAKA, K.; OHNO, N.; ADACHI, Y.; MIURA, N. N.; YADOMAE, T. Application of Candida solubilized cell wall $\beta$-glucan in antitumor immunotherapy against P815 mastocytoma in mice. Internacional Immunopharmacology, Amsterdam, v.2, n. 1, p.59-67, 2002.

TORTORA, G. F.; BERDELL, R.; CASE, C. L. Microbiologia. In: Fungos, Algas, Protozoários e Parasitas Multicelulares. 6. ed. Porto Alegre: Artmed, 2000. p. 320-358.

TSIAPALI, E.; WHALEY, S.; KALBFLEISCH, J.; ENSLEY, H. E.; BROWDER, I. W.; WILLIANS, L. D. Glucans exhibit weak antioxidant activity, but stimulate macrophage free radical activity. Free Radical Biology and Medicine, New York, v. 30, n. 4, p. 393-402, 2001.

TSUKADA, C.; YOKOYAMA, H.; MIYAJI, C.; ISHIMOTO, Y.; KAWAMURA, H.; ABO, T. Immunopotentiation of intraepithelial lymphocytes in the intestine by oral administrations of $\beta$-glucan. Cellular Immunology, v. 221, n. 1, p. 1-5, 2003. 
TZIANABOS, A. O. Polysaccharide immunomodulators as therapeutic agents: structural aspects and biologic function. Clinical Microbiology Reviews, Washington, v. 13, n. 4, p. 523-533, 2000.

TZIANABOS, A. O.; CISNEROS, R. L. Prophylaxis with the immunomodulator PGG glucan enhances antibiotic efficacy in rats infected with antibiotic-resistant bacteria. Annals of the New York Academy of Sciences, New York, v. 797, n. 1, p. 285-7, 1996.

XIA, Y.; ROSS, G. D. Generation of recombinant fragments of CD11b expressing the functional $\beta$-glucan binding lectin site of CR3 (CD11b/CD18). Journal of Immunology, Baltimore, v. 162, n. 12, p. 7285-7293, 1999.

XIAO, Z.; TRINCADO, C. A.; MURTAUGH, M. P. $\beta$ Glucan enhancement of $\mathrm{T}$ cell IFN-gamma response in swine. Veterinary Immunology and Immunopathology, Amsterdam, v. 102, n. 3, p. 315-320, 2004.

YOUNG, S.-H.; JACOBS, R. R. Sodium hydroxideinduced conformational change in schizophyllan detected by the fluorescence dye, aniline blue. Carbohydrate Research, Amsterdam, v. 310, n. 1, p. 91-99, 1998.

WAKSHULL, E.; BRUNKE-REESE, D.; LINDERMUTH, J.; FISETTE, L.; NATHANS, R. S.; CROWLEY, J. J.; TUFTS, J. C.; ZIMMERMAN, J.; MACKIN, W.; ADAMS, D. S. PGG-glucan, a soluble $\beta$-(1,3)-glucan, enhances the oxidative burst response, microbicidal activity, and activates an NF-kappa B-like factor in human PMN: evidence for a glycosphingolipid $\beta$-(1,3)-glucan receptor. Immunopharmacology, New York, v. 41, n. 1, p. 89-107, 1999.
WATERS, M. D.; BRADY, A. L.; STACK, H. F.; BROCKMAN, H. E. Antimutagenicity profiles for some model compounds. Mutation Research, Amsterdam, v. 238, n. 1, p. 57-85, 1990.

WHEELER, R. T.; FINK, G. R. A drug-sensitive genetic network masks fungi from the immune system. PLoS Pathogens, San Francisco, v. 2, n p. 328-339, 2006.

WILLIAMS, D. L.; MUELLER, A.; BROWDER, W. Glucan-based macrophage stimulators. Clinical Immunotherapy, Local, v. 5, n. 5, p. 392-399, 1996.

WILlmeNT, J. A.; GORDON, S.; BROWN, G. D. Characterization of the human $\beta$-glucan receptor and its alternatively spliced isoforms. The Journal of Biological Chemistry, Bethesda, v. 276, n. 47, p. 43818-43823, 2001 .

WILSON, T. A.; NICOLOSI, R. J.; DELANEY, B.; CHADWELL, K.; MOOLCHANDANI, V.; KOTYLA, T.; PONDURU, S.; ZHENG, G. H.; HESS, R.; KNUTSON,N.; CURRY, L.; KOLBERG, L.; GOULSON, M.; OSTERGREN, K. Reduced and high molecular weight barley $\beta$-glucans decrease plasma total and non-HDL-cholesterol in hypercholesterolemic syrian golden hamsters. Journal of Nutrition, Philadelphia, v. 134, n. 10, p. 2617-2622, 2004.

ZIOTNIK, H.; FERNANDEZ, M. P.; BOWERS, B.; CABIB, E. Saccharomyces cerevisiae mannoproteins form an external cell wall layer that determines wall porosity. Journal of Bacteriology, Washington, v. 159, n. 3, p. 1018-1026, 1984. 
